ELORE (ISSN 1456-3010), vol. $14-2 / 2007$.

Julkaisija: Suomen Kansantietouden Tutkijain Seura ry.

[http://www.elore.fi/arkisto/2_07/knu2_07.pdf]

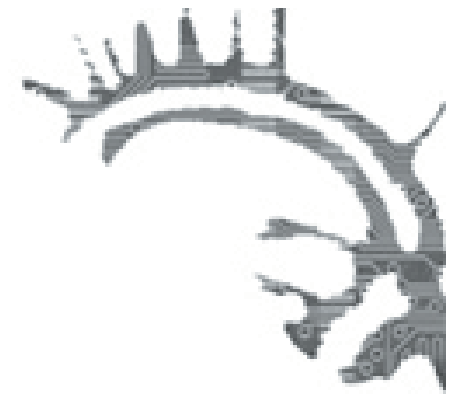

\title{
KolumNi: \\ MUISTAAKO KUKAAN, TAPAHTUUKO MITÄÄN?
}

\section{$\underline{\text { Seppo Knuuttila }}$}

Viime vuodenvaihteen molemmin puolin järjestettiin kaksi muistitiedon tutkimuksen kannalta tärkeätä konferenssia, ensimmäinen Helsingissä otsikolla "Memory and Narration" (15.-17.11.2006) ja toinen Tartossa "Memory from Transdisciplinary Perspectives" (11.-14.1.2007). Molemmissa konferensseissa, joista on raportoitu Eloren numerossa 1/2007, oli edustava joukko esityksiä, jotka laajasti ottaen tematisoivat kulttuurisen muistin problematiikkaa. Yhdistävä metodologinen näkökulma puolestaan oli artikulaatiokehys, jota tosin kukaan kuulemistani puhujista ei eksplisiittisesti käsitellyt, vaikka kytkentä oli ilmeinen. Muistin, tekstin ja kontekstin suhde tuli esityksissä ilmi siten, että se, mitä muistettavana käsiteltiin, sijoitettiin menneisyyteen, mutta muistettuna esitetyt tekstit paikannettiin etnografiseen nykyhetkeen (joku kertoo nyt, mitä silloin tapahtui). Nämä kysymykset jäivät askarruttamaan mieltäni; pohdin niitä alustavasti jo Suomen Kansantietouden Tutkijain Seuran kevätkoulussa ja jatkan "jotakin on tapahtunut ja tapahtuu" -teemasta tässä.

Muistitietotutkimuksen ydinkysymyksiin kuluu ajallisuuden käsittely, koska muisti konstruoi tapahtuneen suhdetta olevaan. Niinpä nyt-hetkeä laajentaviin ajallisuuksiin sisältyy anakronismin potentiaali, joka yhtälälä viittaa mahdollisuuteen ymmärtää mennyttä nykyisyyden eli tiedetyn valossa, ja toisaalta se sisältää erehdyksen mahdollisuuden olettaa ja kuvata menneisyys nykyisyyden heijastumana.

Traditioiden katkoksia propagoivat väittämät menneisyyden olemattomuudesta päätyvät tavallaan samaan otaksumaan radikaalin konstruktivismin kanssa, jonka mukaan menneisyys on aina konstruoitua ja sen esitykset voivat toteutua vain kulloisessakin nykyisyydessä. Eli menneisyys on kulttuurinen konstruktio, joka on olemassa vain esitettynä. Koska menneisyyden kieltäminen ei ole kuitenkaan folkloristiikan näkökulmasta hyödyllinen etenemissuunta, kannattaa pikemmin pohtia sellaisia menneisyyden tuottamisen jokapäiväisiä käytäntöjä, joissa jotakin esitetään olleeksi, tapahtuvaksi, tulevaksi - samaan hengenvetoon, yhdellä lauseella, jopa yhdellä kieliopillisella johdoksella ja teonsanan ajallistavalla muodolla. 


\section{MUISTAAKO KUKAAN, TAPAHTUUKO MITÄÄN?}

\section{LIKIARVOJEN AAVE}

Muuttuvan maailman pitkä pohdintahistoria kertaa jatkuvasti sitä, mitä ollaan menettämässä ja mihin muutosten jälkeen ei ole enää paluuta. Yhdenmukaistuvan ja pinnallistuvan maailman kuvaaminen on ollut suosittua nimenomaan yhteiskuntakritiikkinä. Seuraavan tapaiset fragmentit ovat esimerkkejä siitä, miten muutoksiin viitataan ja kuinka muuttuvan maailman käsitehistoriaa konstruoidaan ja pidetään yllä:

Ihmisrodun variaatio on katoamassa; samoja käyttäytymisen, ajattelemisen ja tuntemien tapoja voi kohdata kaikkialla maalimassa. Tämä ei johdu vain siitä, että kansakunnat ovat entistä enemmän tekemisissä toistensa kanssa ja jäljittelevät toisiaan entistä enemmän, vaan myös siitä, että ihmiset yhä enenevässä määrin luopuvat omista asemaa, ammattia tai perhettä koskevista käsityksistä ja sillä tavoin lähestyvät vähitellen ihmisen perusluonnetta, mikä on samanlainen kaikkialla. Näin ihmisistä tulee yhä enemmän toistensa kaltaisia ilman että heidän tarvitsee jäljitellä toisiaan. (de Tocqueville 1835-1849/Relph 1976.)

Ja epäilemättä aikamme suosii kuvaa asian, jäljitelmää alkuperäisen, miellettä todellisuuden, ilmenevää olevaisen sijaan (Feuerbach 1841/ Debord 1967.)

Kun yhteiskunnan ja kulttuurin tutkijat ovat käsitelleet muutoksia tutkimuskohteissaan, he tapaavat päätyä vertailuasetelmaan, jossa "ennen" ja "jälkeen", "enää" ja "vielä" dominoivat. Tämä on ollut vahvasti konstruoivaa kielenkäyttöä myös perinteentutkimuksessa. Ajalliset kuvaukset yhteiskunnan muuttumisesta ja kansankulttuurin murroksista ovat kuvausten perusarsenaalia, ja ne saavat voimansa tosiasioista, jotka voidaan esittää muun muassa esineiden, tapojen ja taitojen katoamisena. Tällaisten kuvausten implisiittinen argumentti on, että kaikkea tätä loputtomine variaatioineen on kerran ollut olemassa. Ja senkin me tiedämme, että folkloristiset ja etnologiset kuvaukset ovat epätäydellisiä versioita kohteistaan: niissä se, mistä puhutaan, tulkitaan olemassa olleeksi ja sellaiseen menneisyyteen kuuluvaksi, josta on olemassa jonkinlainen jälki. Jäljettömiin kadonneiden objektien paradoksi voi olla sellainen, että meillä on vihï jostakin kerran olleesta mutta ei havaintoa eikä siis varmuutta siitä. Emme saa lopullista, "essentiaalisesti tyydyttävää" vastausta kysymykseen, mikä oli sampo, koska kysymys on epätarkka. Mutta säilötyt tekstit kanssateksteineen seuraavat meitä ja muokkaavat menneisyyttä vastaamalla uusiin kysymyksiin aiemmasta poikkeavilla tavoilla.

\section{SAATIOT JA ISTUMISET}

Sen lisäksi, että laaja nykyisyys tuotetaan tutkimuksissa kertomalla, mitä ei enää ole, oleva kuvataan erilaisina prosesseina ja tendensseinä, jonkun ilmiön vallitsevaksi 


\section{SePpo KNUUTtila}

tulemisena. Pertti Alasuutari on kirjassaan Yhteiskuntateoria ja inbimillinen todellisuus (2007) luonnehtinut modernisaatioteoriaa näennäishistorialliseksi näkökulmaksi, jota käytetään yhteiskuntatieteellisten teorioiden ja kulttuurikritiikin osana. Aina silloin tällöin hänen mukaansa "kansainväliselle yhteiskuntatieteiden yleisölle esitellään uusi tarttuva 'saatio'. Näitä ovat olleet esimerkiksi rationalisaatio, individualisaatio ja sekularisaatio. Eri ajattelijat Alvin Tofflerista Jean-Francois Lyotardiin keksivät säännöllisin väliajoin uusia väitteitä uuden ajan tulemisesta, joka määritellään esimerkiksi 'jälkiteolliseksi', 'postmoderniksi' tai 'globaaliksi'.” (Alasuutari 2007, 208). Tätä samaa "saatio"-puhetta ovat ironisoineet Soile Veijola ja Eeva Jokinen artikkelissaan The Death of the Tourist (1998).

Mutta tapahtumisen preesens on paljon muutakin kuin vain yhteiskunta-ajattelijoiden muotijuttu. "Saatioiden" ohella "(i)stuminen" -johdoksella ja sen istuttamisella neljänteen infinitiiviin tuotetaan jokapäiväisessä puheessa ja päivittäisteksteissä

\section{ISTUMISESIMERKISTÖ}

\section{TILALLISTUMINEN alueellistuminen \\ Innovaatiopalveluiden alueellistuminen ja kan- sainvälistyminen -hanke 2004-2005 (Työelämän tutkimuskeskus, Tampereen yliopisto) \\ eurooppalaistuminen}

Sosiaaliturvan eurooppalaistuminen on fakta (Sosiaali- ja terveysministeriö, 2006)

\section{maapalloistuminen}

Maapalloistuminen on suurimpia kansallisia haasteitamme. (ProAct, 2006)

\section{yhteiskunnallistuminen}

Seminaarin teemoina ovat syömisen ja juomisen yhteiskunnallistuminen (Ruokatutkijoiden syysseminaari 27.9. 2001)

\section{teollistuminen}

Uusi aika ja teollistuminen. (Hämeen liitto.) markkinaistuminen

Kuntapalveluiden markkinaistuminen johtaa palvelujen yhä jyrkempään sosiaaliseen ja alueelliseen eriarvoisuuteen. (Yrjö Hakanen Kuntalehden mukaan 29.3. 2006)

\section{MONINAISTUMINEN \\ erilaistuminen}

Erilaistuminen vai samanlaistuminen? Vertaileva tutkimus paperiteollisuusyhtiöiden ympäristöjohtamisesta (Mika Kuisma 2004)

\section{kulttuuristuminen}

Toinen puoli kehityksessä sitten on markkinoiden kulttuuristuminen (Ylijohtaja Kalevi Kivistön puheenvuoro Ensimmäisessä Suomalais-venäläisessä kulttuurifoorumissa Helsingissä 21.11. 2000)

\section{universaalistuminen}

Kapitalismin protososialistisiin tendensseihin kuuluu näihin muotoihin liittyvien humaanien potentioiden universaalistuminen (Akateemisen Sosialistiseuran manifesti 1995)

\section{VAIHEISTUMINEN}

\section{taiteistuminen}

Taiteistuminen (Levanto, Naukkarinen, Vihma toim. 2005)

\section{mediaalistuminen}

Tämä mediaalistuminen koskee sekä ulkoista että subjektiivista todellisuutta (Jukka Tikkanen: Audiovisuaalinen kulttuuri vuonna 20202, 1995)

\section{maallistuminen}

Yksi tätä vuosisataa ilmentäviä sanoja on maallistuminen (John Vikström Suomen kristillisen opettajaliiton kokouksessa Turussa 5.10. 1996) 


\section{MUISTAAKO KUKAAN, TAPAHTUUKO MITÄÄN?}

deskriptiivisiä väitteitä, joiden mukaan me elämme kiihkeiden muutosten aikaa - ehkä niin onkin - , jolloin mitä moninaisimmat asiat ovat joko äskettäin tulleet tai parhaillaan tulevat vallitseviksi. Ja toden totta, esimerkiksi "autoistumisella" on seurauksensa "kaikkiallistumisesta" puhumattakaan. Niin "saatiot" kuin "istumisetkin" implikoivat jonkin päättymistä, väistymistä, katoamista. Tai R. Williamsia mukaillen orastavaa jo vallitsevaksi väittäessään "istumis" -teesit konstruoivat menneisyyden kaikuja ikään kuin todisteiksi tulevasta. Margariinistumisen sepitteelliseen saturaatioon päästiin, kun mainoksissa alettiin ihmetellä, mitä ja millaista oli ennen Floraa. Nykyään "istumisen" kulttuuri- ja yhteiskuntateoriaa, muutoksen toiveita ja pelkoja tuotetaan istumisesimerkistön (s. 3) tapaisin toteamuksin.

\section{Menneen tapahtumattomuUs}

Katoavuuden tunne ja siitä muistuttaminen olivat eritoten 1600-luvun vanitas-maalausten keskeissisältöä: elämä kulkee alusta lähtien vääjäämättömästi kohti kuolemaa. J.-F. Lyotard on puolestaan kiinnittänyt kirjoituksessaan Ylevä ja avantgarde (1986) huomiota siihen, miten ahdistuksen tunne on usein liitetty mahdollisuuteen, "että mitään ei tapahdu". Hieman mutkia oikoen: "Pelottavaa on, että Se tapahtuu (Il arrive)

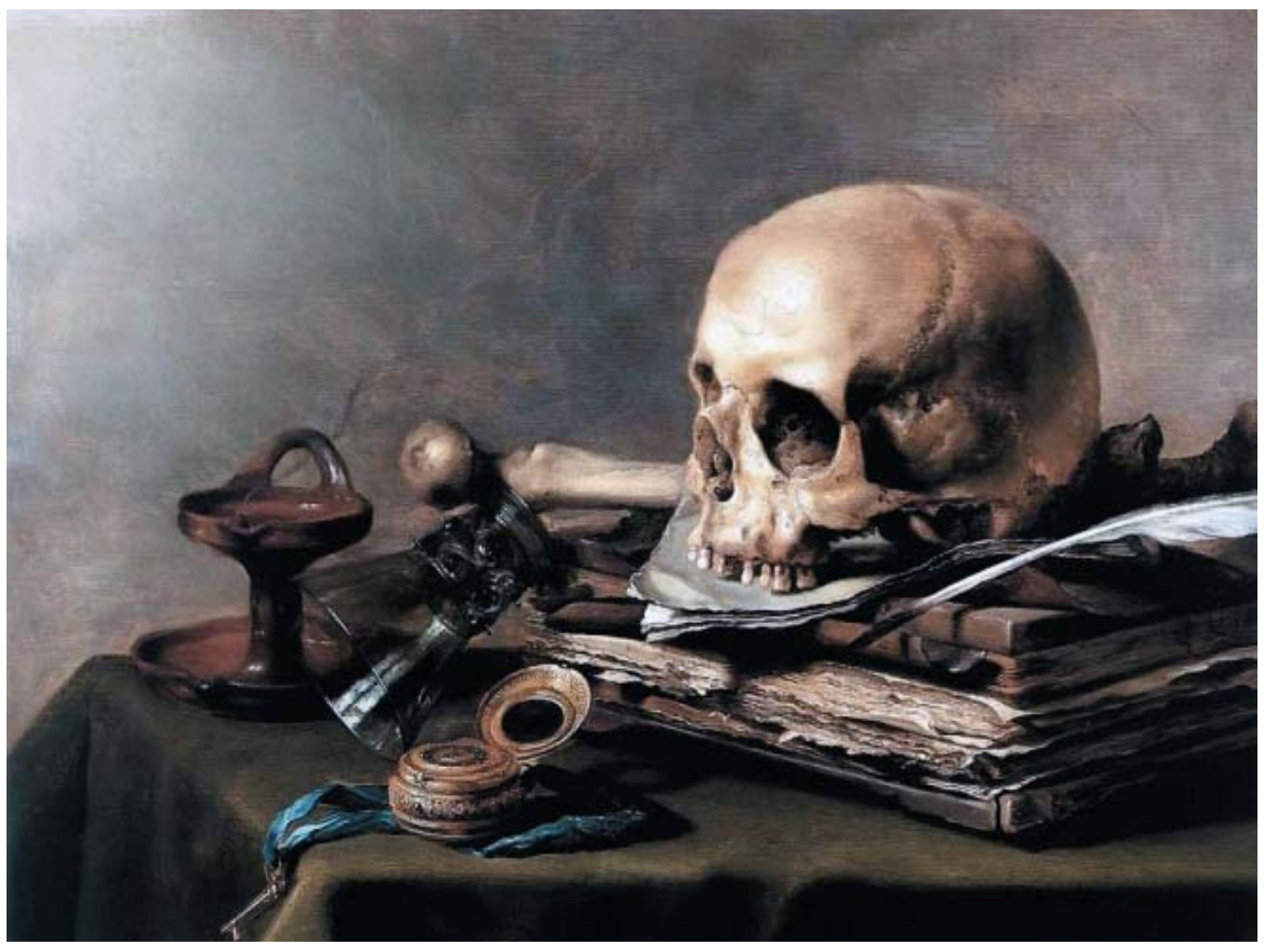

Pieter Claesz. (n.1597-1661): Vanitas-asetelma, 1630. Mauritzhuis, Haag. Kuva: Web Gallery of Art. 


\section{SePpo KNUUTtila}

-tapabtuma ei tapahdukaan, sen tapabtumisen lakkaaminen." Että saatiot ja istumiset eivät toteudukaan, vaan ikään kuin hiipuvat nyt-hetkeen.

Nykyisen kulttuurintutkimuksen piirissä, joka on folkloristiikankin haastava ja antoisa tieteellinen konteksti, vallitsee lievä yksimielisyys siitä, että millaisista teksteistä tahansa voidaan konstruoida tutkimusaineistoja. Kun periaatteessa kaikki käy, tutkimusaineiston muodostaminen on metodisesti entistä vaativampi tehtävä. Samoin lähdekritiikille, refleksiivisyyden käytännölle asetettavat vaatimukset ovat sitä moninaisemmat, mitä useammanlaisia tekstejä ja konteksteja tutkimuslähteisiin sisältyy. Kun aika ja paikka ovat käsitteellisesti moninaistuneet ja jokainen fragmentti voi saada toisesta poikkeavan merkityksen, alkaa ns. annetun myyttikin vaikuttaa väärän olemuksellisuuden sijasta meitä menneeseen sitovan ajattelun työkalulta. Vaikka voisit saada jonkin paikan tai alueen kulttuurista tuhansia kuvauksia, jotka kaikki ovat oikeita, niin tutkimuksen näkökulmasta on kiinnostavaa, mikä näitä kaikkia oikeita kuvauksia yhdistää, miten niiden ilmaisut vastaavat ilmaistua tai milloin aiemmin esitetyt kysymykset muuttuvat epärelevanteiksi, lakkaavat kiinnostamasta tai saavat kokonaan uusia merkityksiä.

Mitä eheämpään kertovaan esitykseen etnografiassa pyritään, sitä vahvempi on esityksen konstruktivistinen ote. Rajatuilla kysymyksillä ja esityksellä voidaan puolestaan tavoittaa kokonaishahmotusta täsmällisemmin niitä kohteita ja piirteitä, joista halutaan tietoa. Etnografinen kokonaisesitys on parhaimmillaankin tiedollisesti vähemmän mutta tulkinnallisesti enemmän kuin osiensa summa. Tätä läpinäkyvää paradoksia pohdittiin laajasti "writing culture"-keskustelussa 1980-luvun lopulla. Pitkäkestoisetkaan kenttätyöt eivät konstruktivistisen etnografiakäsityksen mukaan ole koskaan edenneet suoraviivaisesti ensimmäisistä yksittäisistä havainnoista kohti sellaista tilaa, jossa uutta informaatiota ei enää olisi saatavissa ja jossa mitään ei enää tapahtuisi.

Kaikki hyvin perustellut todet uskomukset niin harkitusti muodostetuissa aineistoissa kuin osaavasti johdetuissa tutkimustuloksissakin ovat yleisesti ottaen olemassa suhteessa siihen, mitä on kysytty ja mitä on haluttu tietää. Mutta folkloristiikan pitkän intressin tuloksina syntyneet tekstit ovat yhteydessä myös sellaisiin kulttuurin tekijöihin, joista ei ole ymmärretty kysyä mitään, joita ei välttämättä ole edes huomattu tai jotka on tulkittu omien mieltymysten mukaisesti tavoittamattomiksi, ei enää koskaan tapahtuviksi. Vaikka mennyt katoaakin kokemuspiiristämme, niin kuin se ajallisesti tekee - ja niin teemme mekin - sen säikeet kiertyvät nykyisyyteen lukemattomin eri tavoin. Osa menneen vaikutuksista jatkaa ohitsemme tulevaisuuteen, jossa ne sekoittuvat meille tuntemattomien ainesten kanssa uusiksi saatioiksi, istumisiksi ja tiesmiksi.

\section{KirjallisuUs}

ALASUUTARI, PERT'TI 2007: Yhteiskuntateoria ja inbimillinen todellisuns. Helsinki: Gaudeamus.

DEBORD, GUY 2005: Spektaakkelin yhteiskunta. Helsinki: Summa. [1967] 


\section{MUISTAAKO KUKAAN, TAPAHTUUKO MITÄÄN?}

LYOTARD, JEAN-FRANCOIS 1986: Ylevä ja avantgarde. - Kotkavirta, Jussi \& Sironen, Esa (toim.), Moderni / postmoderni: läbtökobtia keskusteluun. Helsinki: Suomen Tutkijaliitto.

RELPH, E. 1976: Place and Placelessness. London: Pion.

VEIJOLA, SOILE \& JOKINEN, EEVA 1998: The Death of the Tourist. Seven Improvisations. - European Journal of Cultural Studies 1(3): 327-351.

\section{Istumisesimerkistön Internet-lähteet}

alueellistuminen:

INNOVAATIOPALVELUIDEN ALUEELLISTUMINEN JA KANSAINVÄLISTYMINEN (RISE) -hanke 2004-2005 [online]. <https://tutkii.uta.fi/cris/cris.nsf/ 033d817fb1ba6571422566fe00413417/9a8f414bb600c785c2256e16004bb223?

OpenDocument> [12.9.2007.]

eurooppalaistuminen:

SOSIAALI- JA TERVEYSMINISTERIÖ. Tiedote 9.11.2006 [online]. <http://www.stm. fi/Resource.phx/publishing/documents/9125/index.htx> [12.9.2007.]

maapalloistuminen:

ProACT 2006 [online]. <http://proact.ktm.fi/print_page.phtml?menu_id=145\&lang=1> [12.9.2007.]

erilaistuminen:

KUISMA, MIKA 2004: Erilaistuminen vai samanlaistuminen?: vertaileva tutkimus paperiteollisuusybtiöiden ympäristöjobtamisesta. Helsinki: Helsinki School of Economics [online]. $<$ http:/ /hsepubl. lib.hse.fi/FI/diss/?cmd=show\&dissid=255> [12.9.2007.]

\section{kulttuuristuminen:}

SUOMALAIS-VENÄLÄINEN KULTTUURIFOORUMI -TOIMINTA. Ylijohtaja Kalevi Kivistön avauspuheenvuoro "Kulttuuriympäristön muutoksia" ensimmäisessä Suomalaisvenäläisessä kulttuurifoorumissa Helsingissä 21.11.2000 [online]. <http://www.kultforum. org/arkisto/helsinki2000/kulttuurifoorumi_kivistonluento.html> [12.9.2007.]

universaalistuminen:

AKATEEMISEN SOSIALISTISEURAN MANIFESTI 1995 [online]. < http://www.helsinki.fi/jarj/ass/julkaisut/manifesti.html> [12.9.2007.]

yhteiskunnalistuminen:

RUOKATUTKIJOIDEN SYYSSEMINAARI 27.9.2001 [online]. < http://www.uta.fi/ajankohtaista/yliopistouutiset/0802/2008c.html> [12.9.2007.]

teollistuminen:

HÄMEEN LIITTO. Uusi aika ja teollistuminen [online]. < http://www.hameenliitto.fi/index. php?id $=759>$ [12.9.2007.]

markkinaistuminen:

KUNTALEHTI 29.3.2006. Kuntapamfletti: Puitelaki valmiiksi vasta eduskuntavaalien jälkeen [online]. <http: / www.kuntalehti.fi/default.asp?sc $=3034 \& s a=75593>$ [12.9.2007.]

taiteistuminen:

LEVANTO, YRJÄNÄ \& NAUKKARINEN, OSSI \& VIHMA, SUSANN (toim.) 2005: Taiteistuminen. Taideteollinen Korkeakoulu: Helsinki [online]. < http://granum.uta.fi/granum/kirjanTiedot.php?tuote_id=13515 > [12.9.2007.]

mediaalistuminen:

TIKKANEN, JUKKA 1995: Audiovisuaalinen kulttuuri vuonna 2020 [online]. <http://www. internetix.fi/uutiset/netixpress/0200/audio.htm> [12.9.2007.] 
SEPPO KNUUTTILA

maallistuminen:

VIKSTRÖM, JOHN 1996: Pyhän ja arjen merkitys. Suomen kristillisen opettajaliiton kokouksessa Turussa 5.10.1996 [online]. <http://www.evl.fi/arkkipiispa/pyha.htm > [12.9.2007.]

Seppo Knuuttila on Joensuun yliopiston perinteentutkimuksen professori. 